\title{
ECCENTRIC LOADING BEHAVIOR OF L-SHAPED COLUMNS COMPOSED OF CONCRETE-FILLED STEEL TUBES
}

\author{
T. Zhou ${ }^{1}$, M.Y. Xu' ${ }^{2}$ Z.H. Chen ${ }^{3}$, X.D. Wang ${ }^{4, *}$ and Y.W. Wang ${ }^{5}$ \\ ${ }^{1}$ Lecturer, School of Architecture, Tianjin University, China \\ ${ }^{2}$ Master Candidate, School of Civil Engineering, Tianjin University, China \\ ${ }^{3}$ Professor, School of Civil Engineering, Tianjin University, China \\ ${ }^{4}$ Associate Professor, School of Civil Engineering, Tianjin University, China \\ ${ }^{5}$ Structural Designer, Tianjin University Research Institute of \\ Architectural Design and Urban Planning, China \\ *(Corresponding author: E-mail: maodun2004@126.com)
}

Received: 24 November 2014; Revised: 12 June 2015; Accepted: 9 November 2015

\begin{abstract}
Concrete special-shaped columns have been studied and used in China for twenty years, and can be incorporated into walls to widen indoor areas. However, concrete special-shaped columns do not perform well under seismic action. In addition, special-shaped concrete-filled steel tubular columns were put forward and researched as well because of their high strength and ductility, but the interaction between steel and inner concrete is small. Tie rods are often set to solve the problem, which in turn affect the architectural appearance. To solve the above problems, a special-shaped column composed of concrete-filled steel tubes (SCFT) was proposed and studied. Axial loading behavior, seismic behavior, and whole structure behavior were studied. This type of special-shaped column has been used in residential buildings, and the structural behavior performed well. This paper experimentally investigated the biaxial loading behavior of L-shaped SCFT columns. Failure modes, cooperation of mono-columns, and the effects of eccentric angle and distance on column behavior were studied. Test results were compared with those of finite element analysis. A reasonable simplified calculating formula was proposed based on the study and was proved effectively through the comparison with test results. Mono-columns of SCFT columns proved to work well together. This kind of special-shaped column proved to be a good structure type.
\end{abstract}

Keywords: L-shaped column, concrete-filled steel tube, composite columns, biaxial loading test, finite element analysis, calculating formula

DOI:10.18057/IJASC.2016.12.3.2

\section{INTRODUCTION}

Rapid population growth has led to many problems around the world, especially in China. An increasing number of people have moved from urban to rural areas, and the price of residential buildings has risen rapidly. Therefore, the effective use of land is an important problem. Most residential buildings are built with a concrete structure, and the section of columns is always much larger than the thickness of walls such that columns always occupy inner areas. In recent years, special-shaped columns have been studied to increase utilization areas.

Special-shaped columns are divided according to different construction materials: concrete special-shaped columns (Ramamurthy et al. [1]), steel-reinforced concrete special-shaped columns (Xue et al. [2]), steel fiber high-strength reinforced-concrete and composite columns (Tokgoz et al. [3]), special-shaped concrete-filled steel tube columns (Shen et al. [4]), and special-shaped columns composed of concrete-filled steel tube mono-columns (SCFT columns)(Zhou et al. [5]). 
SCFT columns are composed of several small sections of concrete-filled steel tube columns called mono-columns, which are connected by connection plates. This type of special-shaped column has the advantages of high ductility and low construction cost. SCFT columns have been used in more than 200 residential buildings. In the process of being used, axial loading tests and seismic behavior tests were studied, and the structural static and dynamic behaviors were analyzed using 3D finite element software (Chen et al. [6-7], Zhou et al. [8]. However, eccentric loading behavior has not been researched.

Eccentric loading is one of the most important effect factors of ultimate bearing capacity for columns or walls. For any new structure, eccentric loading behavior should be tested and studied. Kim et al. [9] studied the eccentric loading capacity of high-strength steel-concrete composite columns of various sectional shapes. Halabi et al. [10] studied the behavior of reinforced concrete (RC) slab-column connections strengthened with external carbon fiber-reinforced polymer (CFRP) sheets subjected to eccentric loading. Ernest et al. [11]studied the behavior of textile-reinforced mortar (TRM) strengthened brickwork walls under eccentric compressive loading. Song et al. [12] studied the eccentric behavior of fiber-reinforced polymer (FRP)-strengthened concrete columns. Most studies use the unidirectional bending test, but for asymmetric sections such as special-shaped columns, the real loading condition is biaxial bending.

This paper presents the results of an experimental investigation and analytical simulation of the behavior of eccentrically loaded L-shaped SCFT columns.

\section{EXPERIMENTAL PROGRAM}

\subsection{Introduction}

An experimental study was performed to assess L-shaped SCFT columns under biaxial compression. Three specimens were investigated according to eccentric angle and distance. The main objective of the test was to study the deformation process and failure modes of SCFT columns. The effects of bending direction and eccentric distance on behavior were examined. A finite element model was developed according to the test results.

The cross section shape of L-shaped SCFT columns is monosymmetric; the actual vertical load behavior of this column is compression combined with bending. Three mono-columns were placed under different axial loadings, as shown in Figure 1(a). Under unidirectional lateral force, the load condition could be simplified as uniaxial bending, as shown in Figure 1(b). If bidirectional lateral force was applied to the column, then the load condition could be simplified as biaxial bending, as shown in Figure 1(c). This study investigated the behavior of uniaxial and biaxial bending; axial loading behavior was also tested to study the effect of eccentric loading. The loading positions are shown in Figure 2. The distance between the center of gravity " 0 " and the loading point " $\mathrm{P}$ " is the eccentric distance. The eccentric distances of the uniaxial bending and biaxial bending specimens were the same, whereas the eccentric angles were different.

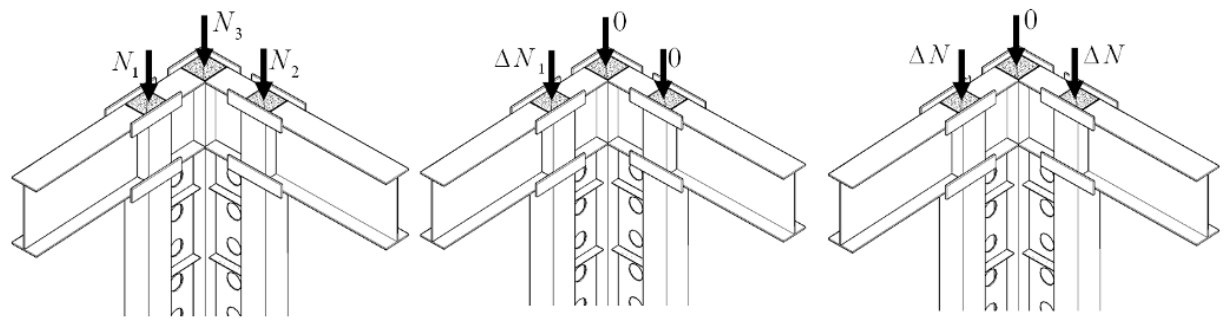

(a) Actual load condition (b) Uniaxial bending (c) Biaxial bending

Figure 1. Simplified Load Condition 


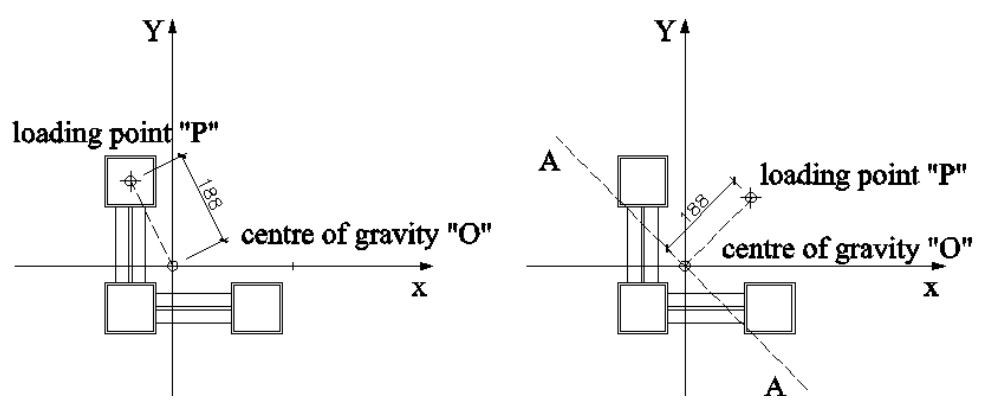

(a) Uniaxial bending (b) Biaxial bending

Figure 2. Loading Position

\subsection{Specimens}

Details of the SCFT column specimens are shown in Figure 3. Both the connection plates and stiffeners were welded onto the steel tubes. Table 1 provides a summary of the specimen details. Material properties of steel and concrete were determined using tensile tests on coupons extracted from the steel tubes and cubes, and cylinder tests on the concrete. Material test results are listed in Tables 2 and 3. Two steel plates with a thickness of $40 \mathrm{~mm}$ were welded to the top and end of the specimens.

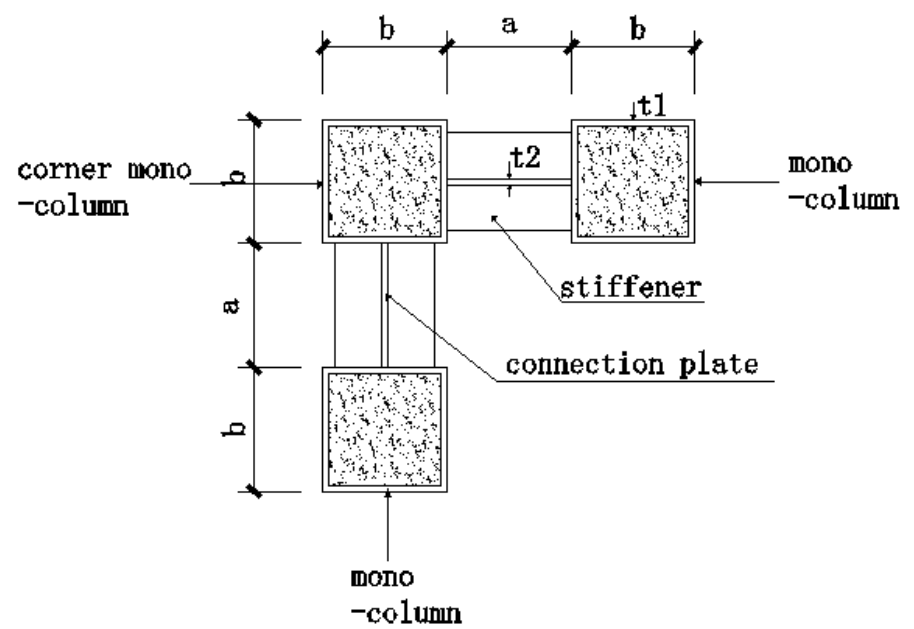

Figure 3. Details of Specimens

Table 1. Summary of Specimens

\begin{tabular}{|c|c|c|c|c|c|c|c|c|c|}
\hline Specimen & $\begin{array}{c}b \\
(\mathrm{~mm})\end{array}$ & $\begin{array}{c}a \\
(\mathrm{~mm})\end{array}$ & $\begin{array}{c}t_{1} \\
(\mathrm{~mm})\end{array}$ & $\begin{array}{c}t_{2} \\
(\mathrm{~mm})\end{array}$ & $\begin{array}{c}A_{y} \\
\left(\mathrm{~mm}^{2}\right)\end{array}$ & $\begin{array}{c}A_{c} \\
\left(\mathrm{~mm}^{2}\right)\end{array}$ & $\begin{array}{c}f_{y} \\
(\mathrm{MPa})\end{array}$ & $\begin{array}{c}f_{c} \\
(\mathrm{MPa})\end{array}$ & $\begin{array}{c}l \\
(\mathrm{~mm})\end{array}$ \\
\hline $\mathrm{S}-1, \mathrm{~S}-2, \mathrm{~S}-3$ & 100 & 150 & 4 & 3 & 1,536 & 8,464 & 269 & 17.336 & 1,500 \\
\hline
\end{tabular}

Table 2. Properties of Steel Tube and Connection Plate

\begin{tabular}{|c|c|c|c|c|c|}
\hline Steel & $\mathrm{t}(\mathrm{mm})$ & $f_{y}(\mathrm{MPa})$ & $f_{u}(\mathrm{MPa})$ & $E_{s}(\mathrm{MPa})$ & $\varepsilon_{y}(\mu)$ \\
\hline Connection plate & 3.00 & 312 & 426 & 148,261 & 2,104 \\
\hline Steel tube & 3.75 & 269 & 445 & 208,305 & 1,291 \\
\hline
\end{tabular}

Table 3. Properties of Concrete

\begin{tabular}{|c|c|c|c|}
\hline Concrete grade & $f_{c u}(\mathrm{MPa})$ & $f_{c}(\mathrm{MPa})$ & $E_{c}(\mathrm{MPa})$ \\
\hline C25 & 23.2 & 17.336 & 19,373 \\
\hline
\end{tabular}




\subsection{Test Setup and Procedure}

The test setup and instrumentation layouts for the L-shaped SCFT column specimens are shown in Figure 4. The uniaxial bending and biaxial bending tests were performed using a reaction frame and a $3000 \mathrm{kN}$ jack, and a spherical hinge was set between the specimen and the reaction frame. To compare the difference between axial loading behavior and eccentric loading behavior, one specimen was compressed using a $5000 \mathrm{kN}$ loading machine.

To describe the experimental results, each mono-column surface was numbered, as shown in Figure 4(d). Figure 4(c) shows that 12 dial meters (numbers 1 to 12) were used to measure the lateral displacements at the top, middle, and end of the specimens. In addition, two dial meters (numbers 14 and 16) were set at the top, while another two dial meters (numbers 13 and 15) were set at the ends of the specimens to measure vertical displacement. Ninety-two strain gauges and two strain rosettes were used for each specimen. Strain gauges and strain rosettes were bonded to the connection plate to determine the directions of principal strains. In addition, 80 strain gauges were bonded to the steel tube of each mono-column at five sections to measure the strains in the tubes along the specimen length. Figure 4(d) shows the strain gauge arrangement on one face of the specimen, which was the same as the other four sections.

Each specimen was loaded manually at low speed. Data were logged at $20 \mathrm{kN}$ intervals before yield and at $10 \mathrm{kN}$ intervals after yield. To apply uniform compressive loading on the columns, two steel plates, each having a thickness of $40 \mathrm{~mm}$, were welded to the two ends of the specimens and allowed to harden under a pre-load of $20 \mathrm{kN}$.

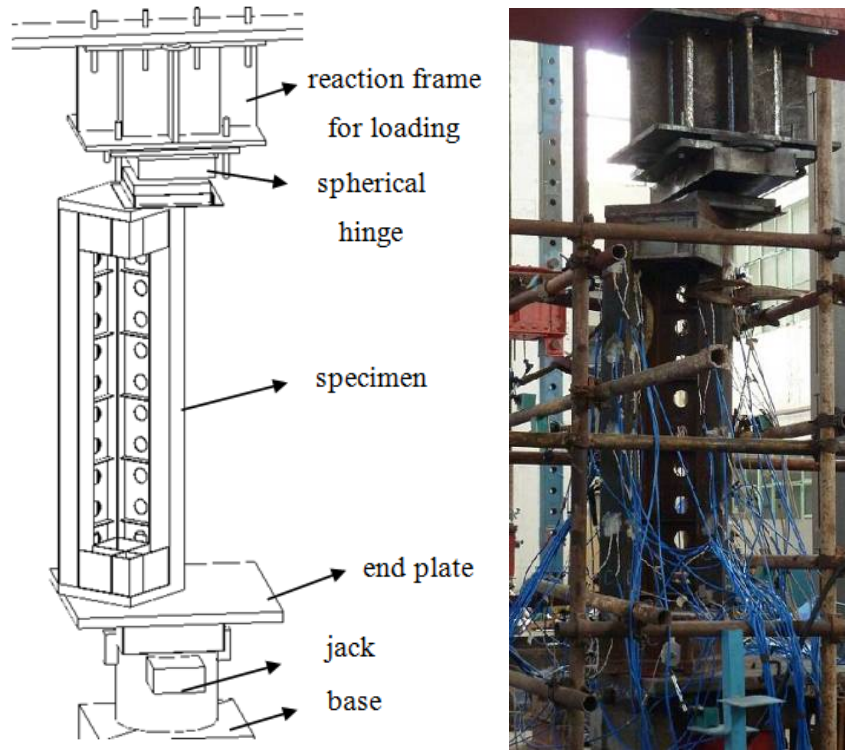

(a) Eccentric compression test setup 


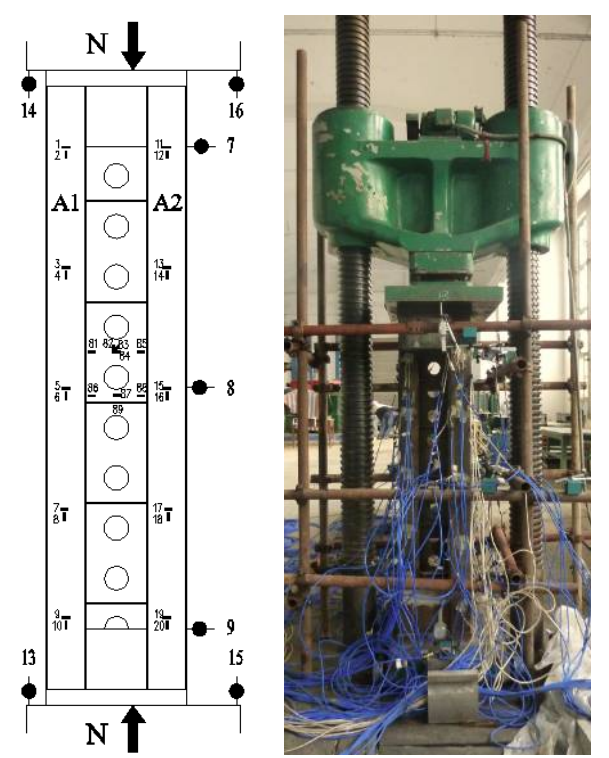

(b) Axial compression test setup
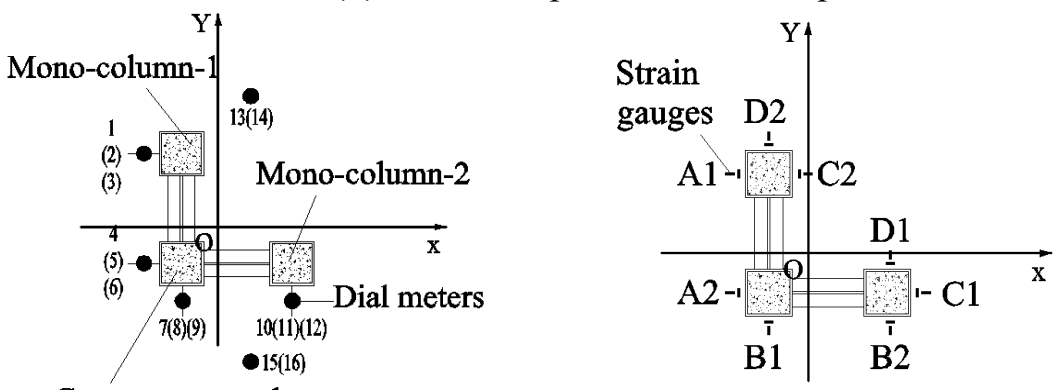

Corner-mono-column

(c) Dial meter layout (d) Strain gauge layout of one of the sections

Figure 4. Test Setup and Instrumentation Layout

\section{TEST RESULTS}

\subsection{Deformation and Failure Mode}

For Specimen S-1, the loading applied to the mono-column was considered uniaxial bending. The failure mode is shown in Figure 5(a). The entire column bent around the x-axis, whereas the bend along the y-axis was not evident. At the top of the mono-column, which was under compression load, the steel tube buckled and the concrete cracked.

For Specimen S-2, the loading position was located at the top steel plate, where no mono-column was under compression load; it was considered biaxial bending. The failure mode is shown in Figure 5(b). The entire column bent around axes $\mathrm{x}$ and $\mathrm{y}$, which means that the column bent around the axis A-A as mentioned in Figure 2(b).

Specimen S-3 was axially compressed by a $5000 \mathrm{kN}$ loading machine. Evident buckling occurred at the top, after which the load decreased rapidly. Mono-column-1 and mono-column-2 exhibited significant buckling at the top, whereas no evident deformation was observed at the corner mono-column. The failure mode is given in Figure 5(c). Although the deformation shapes of the two mono-columns were not the same because of construction error and randomness of the experiment, the failure mode of the specimen is believed to be symmetrical. 


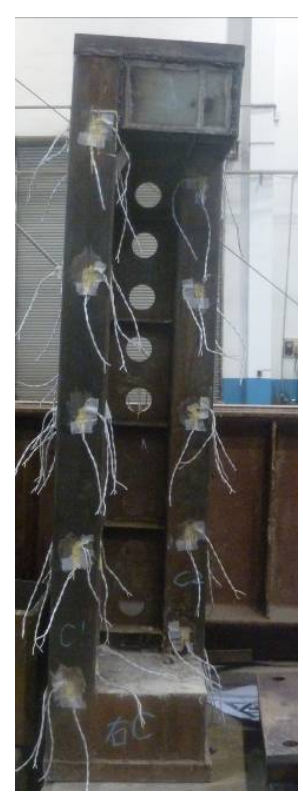

(a) S-1

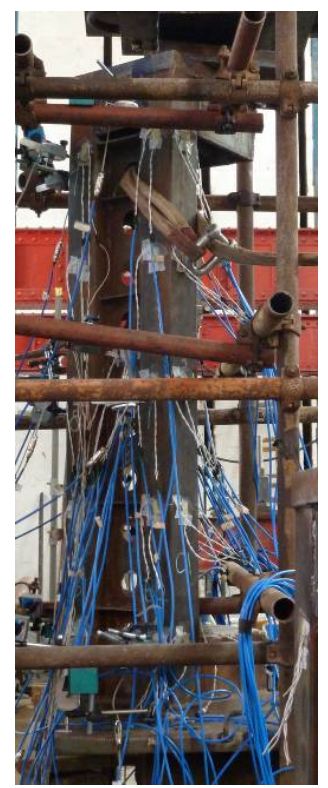

(b) S-2
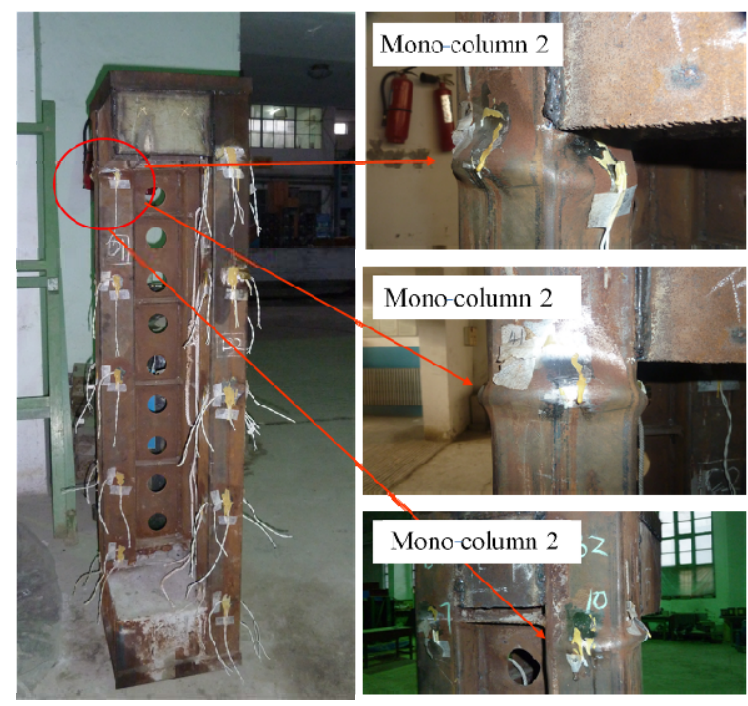

(c) S-3

Figure 5. Failure Modes

\subsection{Vertical Load-End Compressive Displacement}

To gauge vertical deformation, two dial meters were set to measure the downward displacement of the top plate of the loading machine, and another two dial meters were set to measure the upward displacement of the baseboard. The average value of the two dial meters for each plate was considered its displacement. The sum of absolute values of the vertical displacements at the top plate and the baseboard of the press was the end compressive displacement of the specimen. Axial load-compressive displacement curve at the load-end of the two specimens is shown in Figure 6.

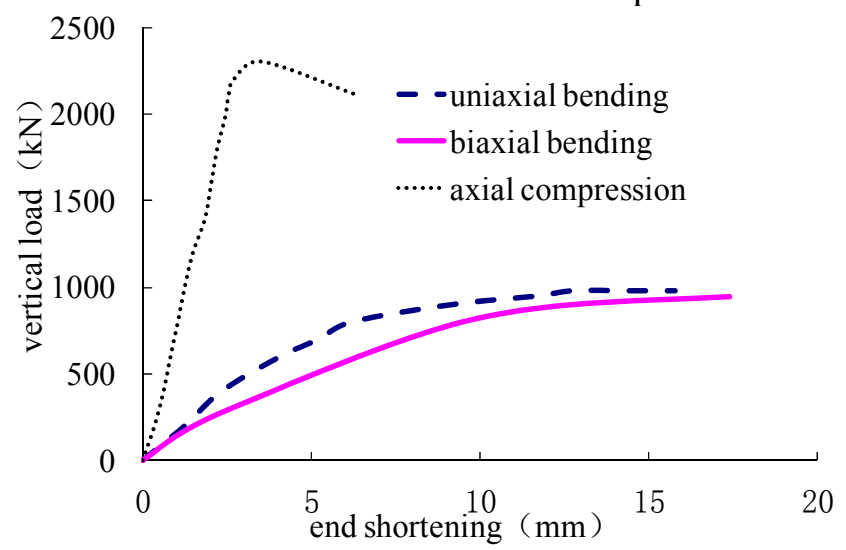

Figure 6. Axial Load-compressive Displacement Curve at Load-end.

The ultimate bearing loads of Specimen S-1 (uniaxial bending), S-2 (biaxial bending), and S-3 (axial compression) were 980, 940, and $2300 \mathrm{kN}$, respectively. The ultimate bearing capacity of Specimens S-1 and S-2 decreased by 57\% compared with the ultimate bearing capacity of Specimen S-3, which means that the eccentric load was adverse. The ultimate loads of Specimens S-1 and S-2 were almost the same, which was caused by an equal eccentric distance of $188 \mathrm{~mm}$ for both specimens. Eccentric load angle is considered to have little influence on ultimate bearing capacity. 


\subsection{Load-lateral displacement curves}

Out-of-plane lateral displacements of the mono-columns were obtained using lateral dial meters. Surface numbers of the mono-columns are shown in Figure 4(d). Figure 7(a) shows that the lateral displacements of areas B1 and B2 of Specimen S-1 were much larger than that of areas A1 and A2. The column section was considered to revolve around the $\mathrm{x}$-axis under uniaxial bending load. However, for Specimen S-2, the lateral displacements of areas A1, A2, B1, and B2 were almost the same, which means that the column section revolved around axis A-A.

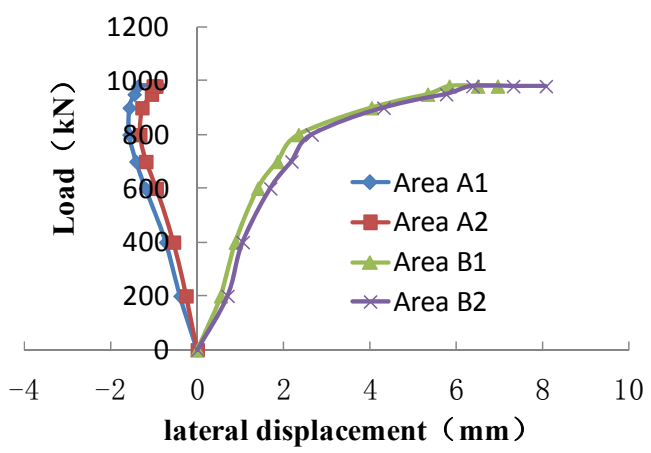

(a) S-1 (uniaxial bending)

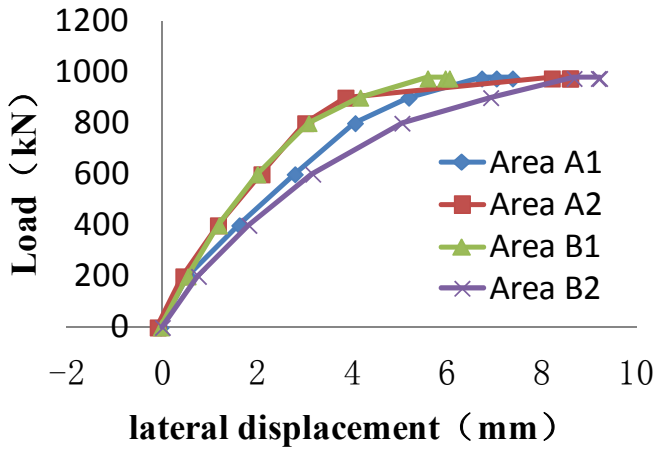

(b) S-2 (biaxial bending)

Figure 7. Axial load-lateral Displacement Curve

\subsection{Lateral Strain Distribution at the Middle Section}

To study strain distribution around the cross section, strain gauges were arranged in the middle section of the column, as shown in Figure 4(c). Figure 8 shows the setup of the strain gauges at the middle cross section. Three load levels $(30 \%, 60 \%$, and $90 \%$ of the ultimate load) were selected to study strain distribution along the cross section. The three load levels for Specimens S-1 and S-2 were set as 400, 600, and $800 \mathrm{kN}$, while those for Specimen S-3 were 600, 1200, and $1700 \mathrm{kN}$. The strain distributions for each load level are shown in Figure 9.

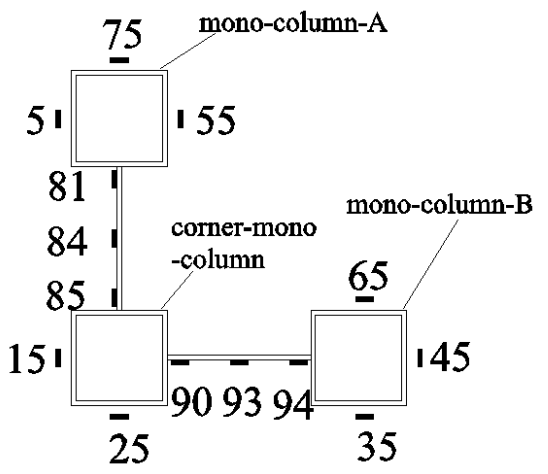

Figure 8. Strain Gauge Arrangement at the Cross Section 


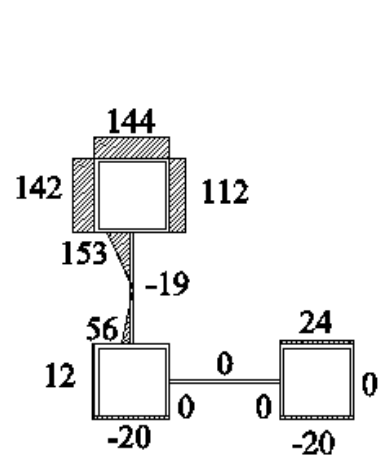

(a) $\mathrm{S}-1400 \mathrm{kN}$

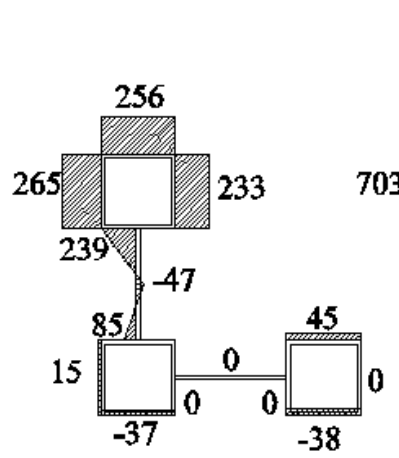

(b) S-1 $600 \mathrm{kN}$

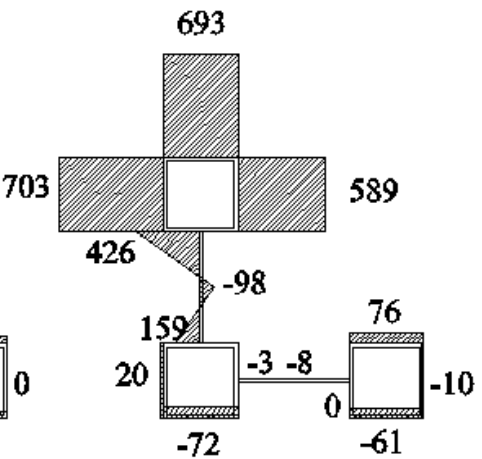

(c) $\mathrm{S}-1800 \mathrm{kN}$
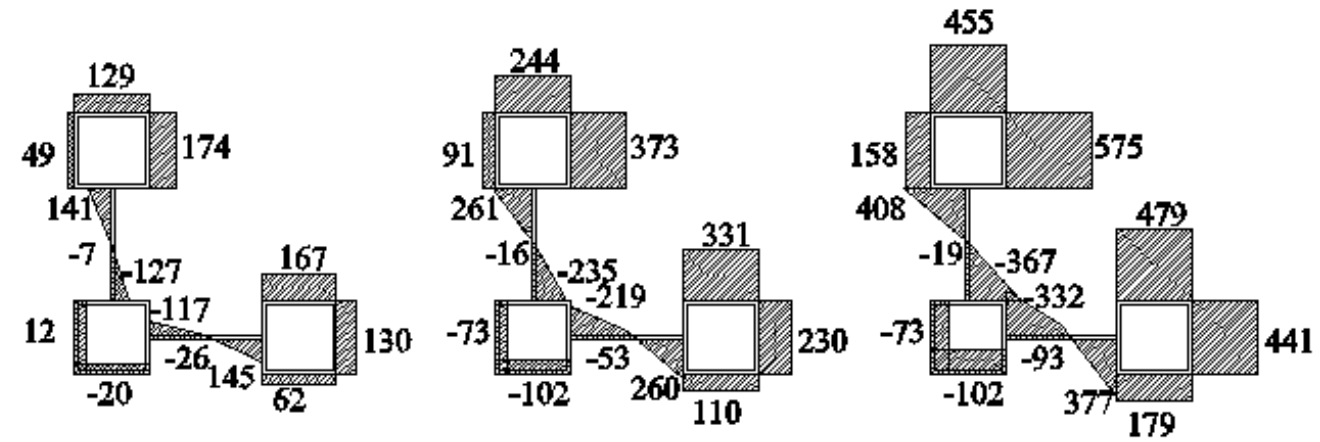

(a) S-2 $400 \mathrm{kN}$

(b) $\mathrm{S}-2600 \mathrm{kN}$
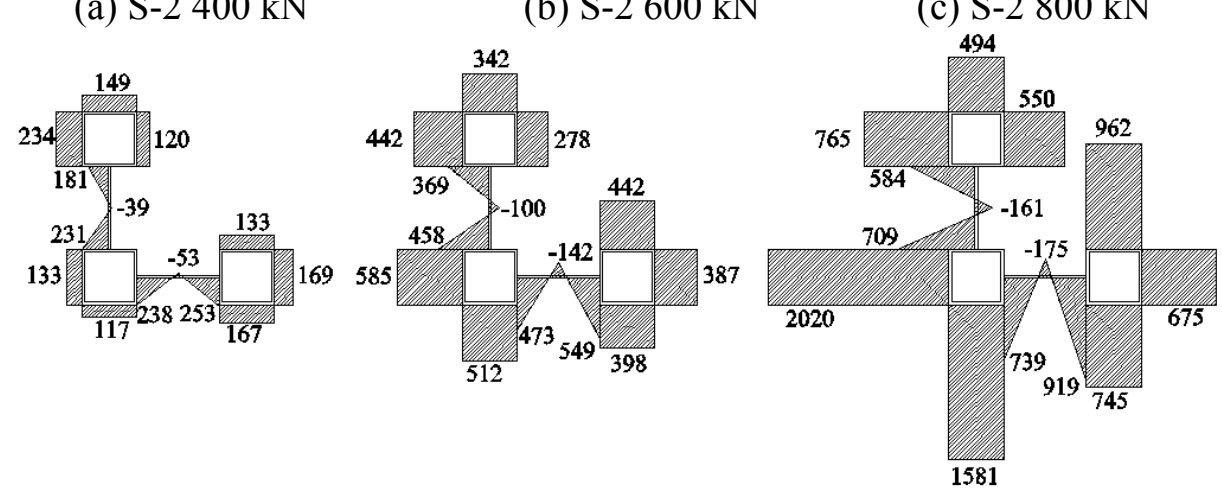
(a) S-3 $600 \mathrm{kN}$
(b) S-3 $1200 \mathrm{kN}$
(c) $\mathrm{S}-31700 \mathrm{kN}$

Figure 9. Strain Distribution of the Cross Section

The strain distribution of Specimen S-1 indicates that the mono-column bore almost all the compression loading. The strains of the other two mono-columns were much lower. The strain sign indicated that the entire column bent around axis $X^{\prime}-X^{\prime}$, as shown in Figure 10(a). Strain distribution and signs of S-2 illustrated that the three mono-columns could work together, and the entire column bent around axis A'-A', as shown in Figure 10(b). Figure 10 shows the bent axes of S-1 and S-2. Hence, the accurately bent axis was found from the cross section strain distribution. The mono-column strains of S-3 were almost the same when the load reached $1200 \mathrm{kN}$, but the strain of the corner mono-column increased rapidly when the load reached $1700 \mathrm{kN}$. 


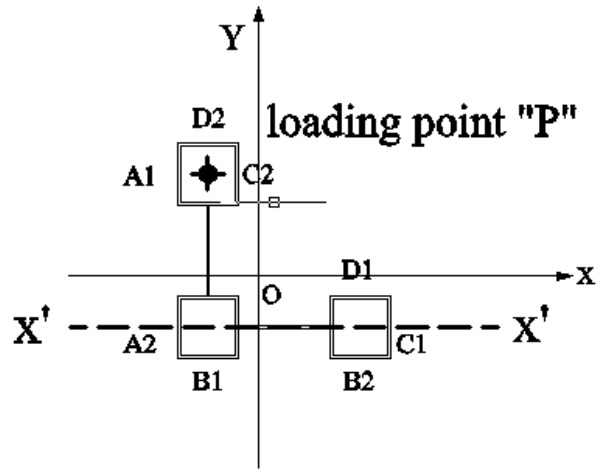

(a) S-1

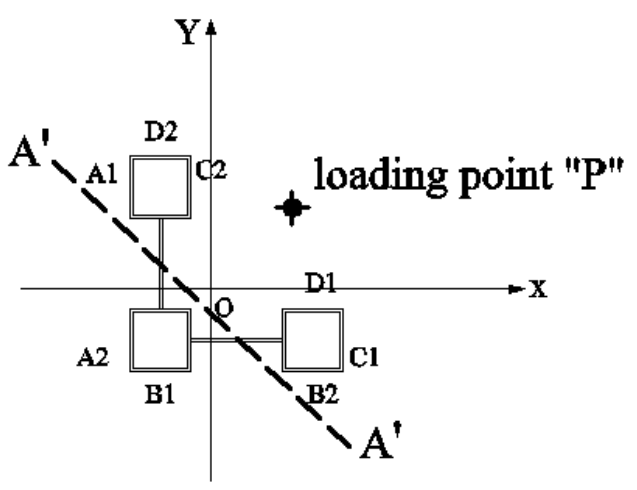

(b) S-2

Figure 10. Bent Axis of S-1 and S-2

The maximum strains of the middle sections of S-1 and S-2 were 703 and $575 \mu$ when the axial load was $800 \mathrm{kN}$, whereas that of S-3 was $2020 \mu$ when the axial load reached $1700 \mathrm{kN}$. The strain of S-3 was significantly larger than that of S-1 and S-2. The steel of S-1 and S-2 did not yield when the load reached $800 \mathrm{kN}$. From the strain distribution, specimen failure under eccentric loading could be concluded to have been caused by instability, whereas that of the axial loading specimen was caused by steel yielding.

\subsection{Lateral Strain Distribution at the Middle Section}

To study the principal stress angle of the middle section of the connection plates, one strain rosette was bonded to the connection plate between areas A1 and A2, while the other was bonded to the connection plate between areas B1 and B2, as shown in Figure 11. The strain rosette consisted of three strain gauges with angles of $0^{\circ}, 45^{\circ}$, and $90^{\circ}$. The $90^{\circ}$ strain gauge was parallel to the length of the steel tube. Principal stress and principal strain were evaluated.

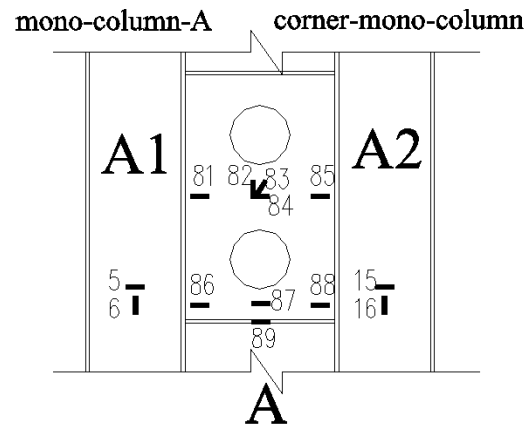

(a) Areas A1 and A2

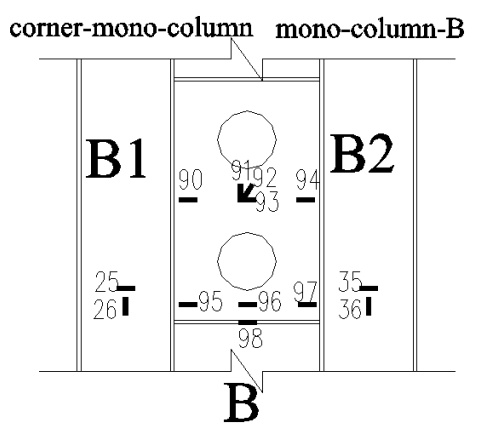

(b) Areas B1 and B2

Figure 11. Strain Rosettes Bonded to the Middle Section of the Connection Plates

The first principal strain $\varepsilon_{1}$ and the second principal strain $\varepsilon_{2}$ of each specimen connection plate are shown in Figure 12. The principal strains of area A and area B were symmetrical for Specimens S-2 and S-3, which indicates that their deformations were symmetrical. The $\theta_{p}$ of all strain rosettes ranged from $35^{\circ}$ to $45^{\circ}$. The principal strain direction of the connection plate is shown in Figure 13. The connection plate could be reduced to a lacing bar with an angle of $35^{\circ}$ to $45^{\circ}$, whereas the stiffener could be reduced to a lateral lacing bar, as shown in Figure 13. 


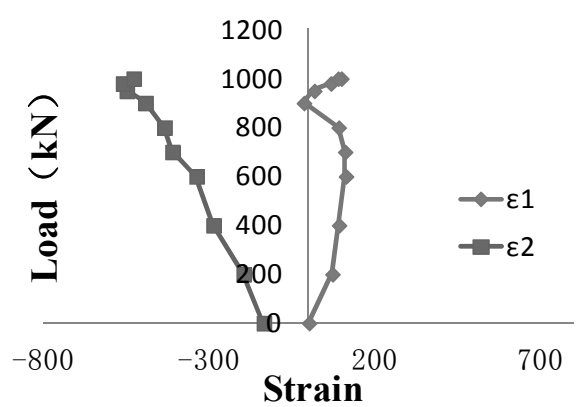

(a) Area A of S-1

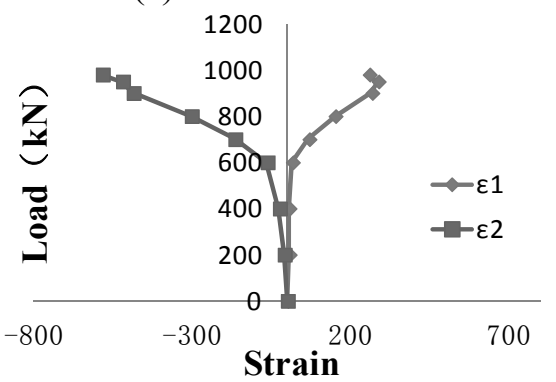

(c) Area A of S-2

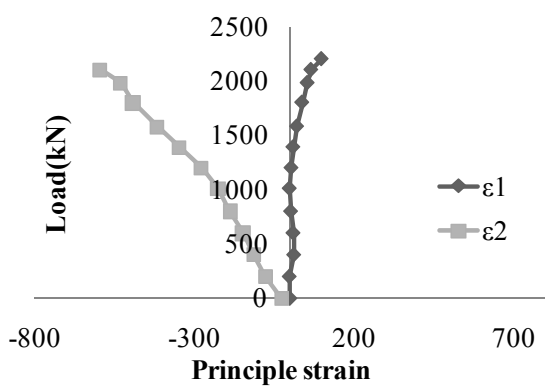

(e) Area A of S-3

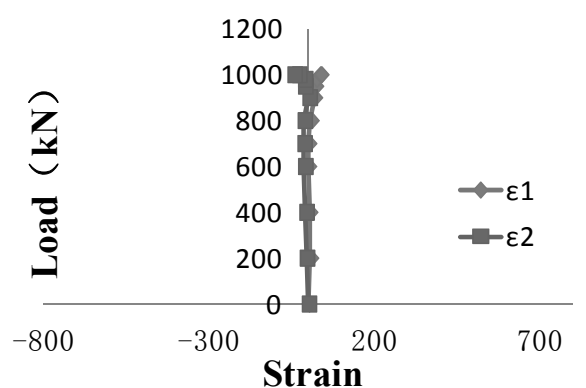

(b) Area B of S-1

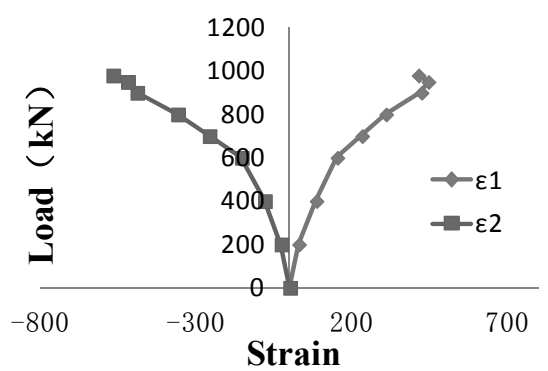

(d) Area B of S-2

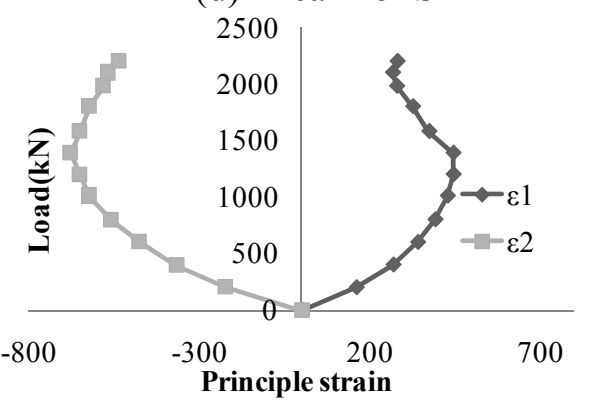

(f) Area B of S-3

Figure 12. Principal Strain of Connection Plate

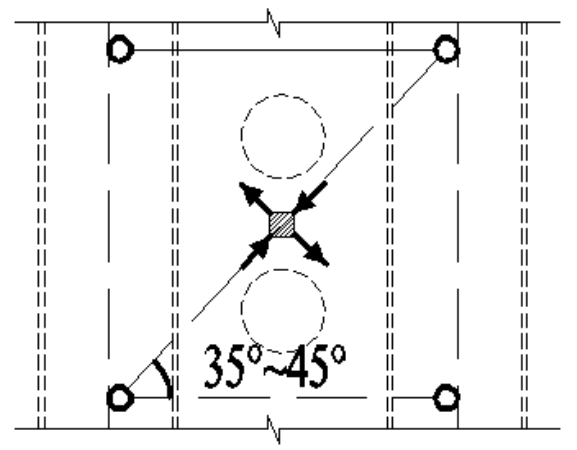

Figure 13. Principal Strain Direction

\section{FINITE ELEMENT ANALYSIS}

A finite element model was established. The behavior of SCFT columns was complicated because of the nonlinearity of the inner concrete and the interaction between the concrete and steel tube. Therefore, a finite element model could provide an efficient method to simulate the behavior of SCFT columns subjected to axial loading. Specimens were modeled and analyzed using the commercial finite element software ANSYS. 


\subsection{Modeling of SCFT columns}

Four main components were modeled to simulate the behavior of SCFT columns: steel tubes, connection plate, inner-filled concrete, and the interface between the concrete and the steel tube. In addition, the selection of element type, mesh size, initial geometric deformation, boundary conditions (fixed at the top and bottom of the column), and load application were also important in simulating the SCFT columns.

SHELL 181 was used to model the steel tubes and bracings. SHELL 181 is a four-node doubly curved shell element that has six degrees of freedom per node. The constitutive law of steel tubes and bracings was assumed elastoplastic with a yielding strain equal to fy/Es. The three-dimensional eight-node element SOLID 65 was adopted to model infilled concrete. Each element node has three degrees of freedom. This element is capable of cracking, crushing, and plastic deformation, and can be used to achieve accurate results in simulating the behavior of concrete under axial loads.

The constitutive law of concrete is the Hognestad type. The constitutive relation of concrete was chosen according to Eqs. 1 to 3, and that of steel was chosen according to Eqs. 4 and 5. $\sigma_{c 0}$ is the compressive strength of concrete achieved in the material test, which equaled $23.2 \mathrm{MPa} . E_{c}$ is the elasticity modulus of concrete, which equaled $19373 \mathrm{MPa} . \sigma_{s 0}$ is the yield strength; the yield strength of the steel tube was $269 \mathrm{MPa}$, and that of the connection plate was $312 \mathrm{MPa} . E_{S}$ is the elasticity modulus of steel, and the elasticity modulus of the steel tube and the connection plate were 208305 and $148261 \mathrm{MPa}$, respectively.

$$
\begin{aligned}
& \left\{\begin{array}{l}
\sigma_{c}=\sigma_{c 0}\left[\frac{2 \varepsilon_{c}}{\varepsilon_{c 0}}-\left(\frac{\varepsilon_{c}}{\varepsilon_{c 0}}\right)^{2}\right] \quad 0 \leq \varepsilon_{c} \leq \varepsilon_{c 0} \\
\sigma_{c}=\sigma_{c 0}\left[1-0.15\left(\frac{\varepsilon_{c}-\varepsilon_{c 0}}{\varepsilon_{c u}-\varepsilon_{c 0}}\right)\right] \quad \varepsilon_{c 0} \leq \varepsilon_{c} \leq \varepsilon_{c u}
\end{array}\right. \\
& \varepsilon_{c 0}=1.8 \sigma_{c 0} / E_{c} \\
& \varepsilon_{c u}=0.0038 \\
& \left\{\begin{array}{l}
\sigma_{s}=E_{s} \varepsilon_{s} \quad 0 \leq \varepsilon_{s} \leq \varepsilon_{s 0} \\
\sigma_{s}=\sigma_{s 0} \quad \varepsilon_{s} \geq \varepsilon_{s 0}
\end{array}\right. \\
& \varepsilon_{s 0}=\sigma_{s 0} / E_{\mathrm{s}}
\end{aligned}
$$

Contact action between the steel tube and the concrete was modeled by contact elements TARGE 170 and CONTA 173. These surface-to-surface contact elements consist of two matching contact faces of the steel tube and concrete elements. The friction between the two faces is maintained as long as the surfaces remain in contact. The coefficient of friction between the two faces was taken as 0.25 in the analysis. These contact elements allow the surfaces to separate under the influence of tensile force, but the contact elements were not allowed to penetrate each other. In addition, the initial imperfections were simulated as follows: compressive unit force was loaded on the 
specimens; the deformation was calculated; and the buckling modal with the concerned deformation was analyzed. (Liu et al. [13])

\subsection{Strain Distribution of Steel and Concrete}

Strain distributions and deformations of the three specimens are shown in Figures 14, 15, and 16. The failure modes were similar to the test results. Specimen S-1 bent around axis X'-X', Specimen S-2 bent around axis A'-A', and Specimen S-3 deformed axially. Based on the deformation and the strain distribution, the strain of each mono-column reached the maximum value; the three mono-columns could work together.
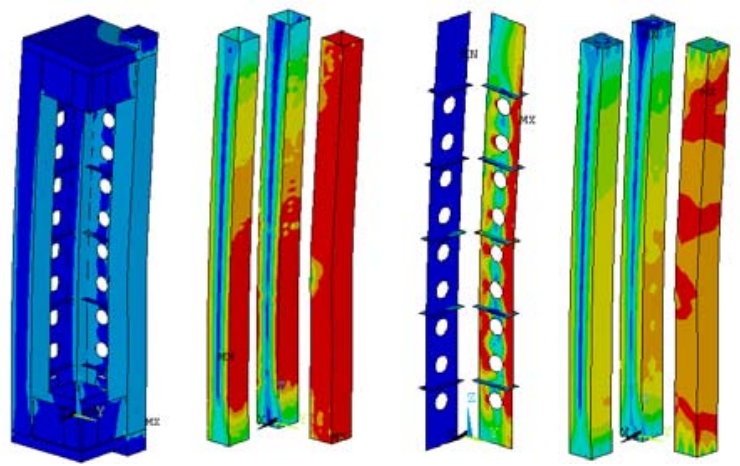

(a) Column (b) Steel tube (c) Connection plates (d) Concrete Figure 14. Strain and Deformation of S-1 (Uniaxial Bending)
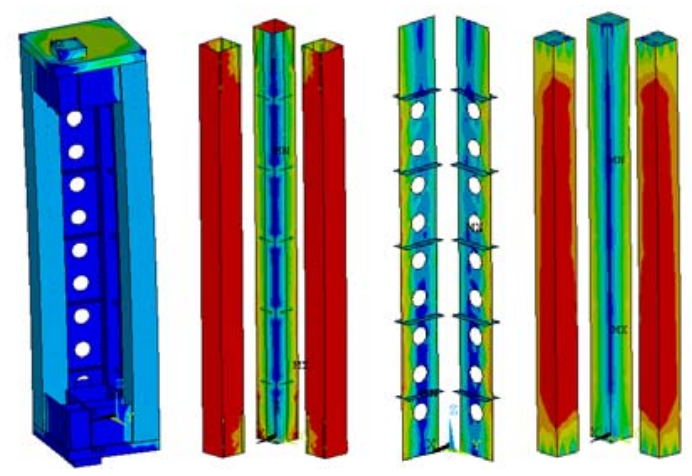

(a) Column (b) Steel tube (c) Connection plates (d) Concrete Figure 15. Strain and Deformation of S-2 (Biaxial Bending)
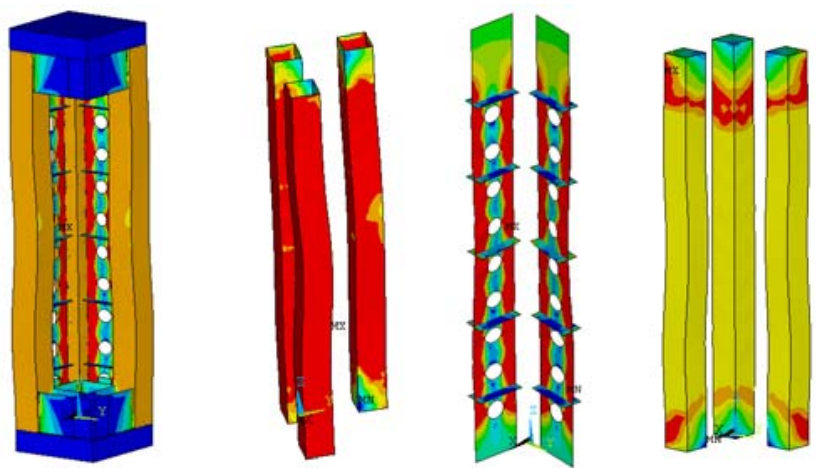

(a) Column (b) Steel tube (c) Connection plates (d) Concrete

Figure 16. Strain and Deformation of S-3 (Axial Loading) 


\subsection{Load-end Compressive Displacement}

According to finite element method (FEM) analysis, the ultimate bearing capacity of Specimens S-1, S-2, and S-3 was 740, 699, and $2113 \mathrm{kN}$, respectively. The load-end compressive displacement curves of the specimens obtained from the experiments and FEM analysis are given in Figure 17. Some differences can be observed between the test results and FEM results of Specimens S-1 and $\mathrm{S}-2$, which were caused by the difference between the real test setup and the FEM model. However, the test and FEM results of Specimen S-3 showed good agreement because the axial loading test was easier to model, which explains the higher ultimate strength gained by FEM. Considering this effect, the results of the finite element analysis agree with those of the experiment.

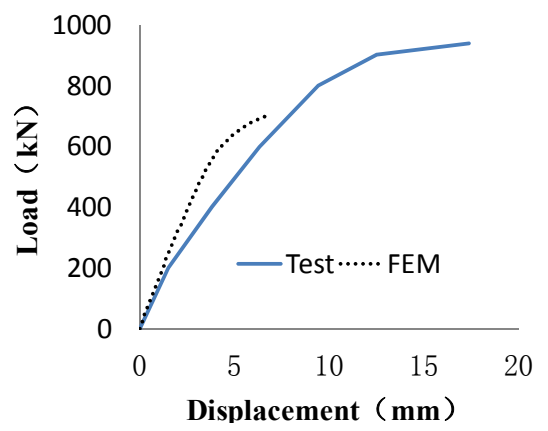

(a) S-1

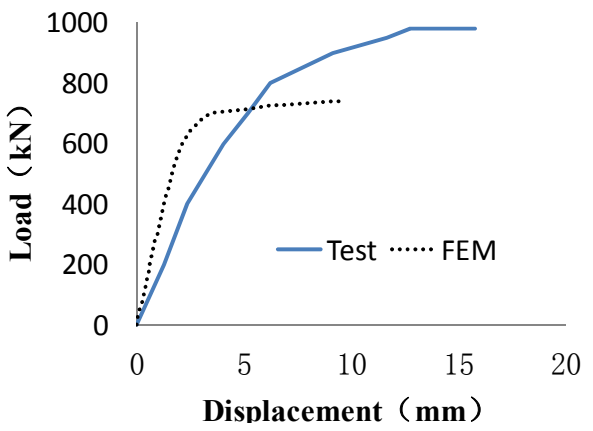

(b) $\mathrm{S}-2$

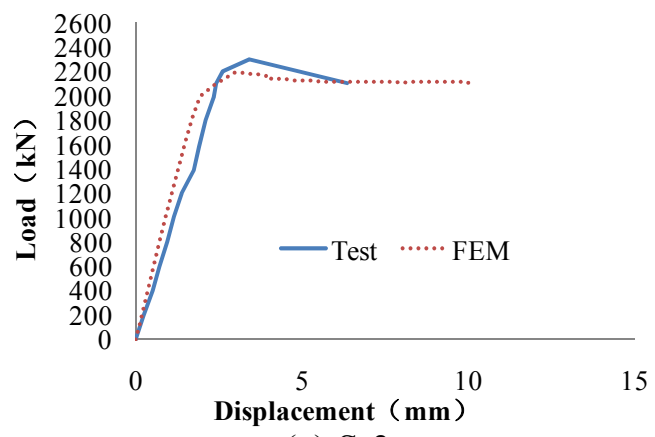

(c) S-3

Figure 17. Comparison of Load-end Compressive Displacement Curves

\section{SIMPLIFIED CALCULATING FORMULA}

According to the strain on the connection plates, the connection plates could be reduced to a lacing bar, and the mono-column was connected by truss. The column is a lattice structure. Eccentric loading $\mathrm{N}$ will lead to bending moment in two directions ( $N e_{x}$ and $N e_{y}$ ). The mono-column bearing axial loading, total loading $\mathrm{N}$, was divided into three axial loadings: N1, N2, and N3. The force diagram is shown in Figure 18, where point " $\mathrm{O}$ " is the center of gravity. The equilibrium equation is shown in Eq. 1. Axial loadings N1, N2, and N3 could be calculated using Eq. 4. If one of the mono-columns failed under axial loading, then the entire column was considered to have failed. If the ultimate axial loadings of the three mono-columns are $N_{1 u}, N_{2 u}$, and $N_{3 u}$, then the ultimate eccentric loading $N_{u}$ can be calculated using Eq. 5. The bearing capacity of each mono-column could be calculated using Eqs. 6-8. If the eccentric distance is large, then the axial load of corner mono-column will be tense, and the concrete is neglected because of poor tension capacity. The stability coefficient $\varphi$ was calculated according to CECS 159: 2004 (China). Calculation results are shown in Table 4. The comparison indicates that the formula results were reasonably accurate. 
Rong [14] studied L-shaped, T-shaped, and X-shaped SCFT columns experimentally, and six specimens were tested under axial loading. Pictures of the test are shown in Figure 19, and test results are shown in Table 5. To verify the accuracy of the calculating formula, a comparison is shown in Table 5. If the section was L-shaped, then there were three mono-columns, and the ultimate bearing capacity could be calculated using Eq. 9. If the section was T-shaped, then we used Eq. 10. If the section was X-shaped, then the corner mono-column was braced by other mono-columns. Thus, the stability coefficient $\varphi$ equaled 1.0, and we used Eq. 11. According to the comparison, the calculating formula proposed in this paper was considered reasonable.

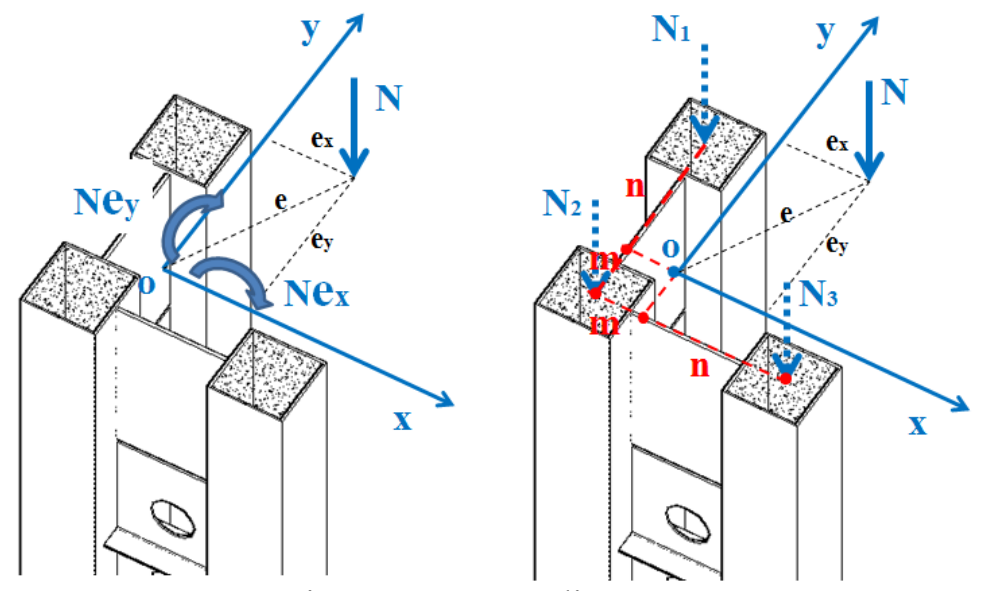

Figure 18. Force diagram.

$$
\begin{aligned}
& \left\{\begin{array}{c}
N=N_{1}+N_{2}+N_{3} \\
N e_{x}=N_{3} n-N_{1} m-N_{2} m \\
N e_{y}=N_{1} n-N_{2} m-N_{3} m
\end{array}\right. \\
& \left\{\begin{array}{c}
m=\frac{a+b}{3} \\
n=\frac{2(a+b)}{3}
\end{array}\right. \\
& \left\{\begin{array}{c}
N=N_{1}+N_{2}+N_{3} \\
N e_{x}=N_{3} n-m\left(N-N_{3}\right) \\
N e_{y}=N_{1} n-m\left(N-N_{1}\right)
\end{array}\right. \\
& \left\{\begin{array}{c}
N_{1}=\frac{e_{y}+m}{m+n} N \\
N_{2}=\frac{n-m-\left(e_{x}+e_{y}\right)}{m+n} N \\
N_{3}=\frac{e_{x}+m}{m+n} N
\end{array}\right. \\
& N_{u}=\min \left\{\frac{m+n}{e_{y}+m} N_{1 u}, \quad\left|\frac{m+n}{n-m-\left(e_{x}+e_{y}\right)}\right| N_{2 u}, \quad \frac{m+n}{e_{x}+m} N_{3 u}\right\}
\end{aligned}
$$




$$
\begin{aligned}
& N_{1 u}=\varphi\left(A_{y} f_{u}+A_{c} f_{c u}\right) \\
& N_{2 u}=\left\{\begin{array}{ccc}
\varphi\left(A_{y} f_{u}+A_{c} f_{c u}\right) \quad\left(\frac{n-m-\left(e_{x}+e_{y}\right)}{m+n}>0 \quad \text { pressure }\right) \\
A_{y} f_{u} \quad\left(\frac{n-m-\left(e_{x}+e_{y}\right)}{m+n} \leq 0 \quad \text { tension }\right)
\end{array}\right. \\
& N_{3 u}=\varphi\left(A_{y} f_{u}+A_{c} f_{c u}\right) \\
& N_{u}=3 \varphi\left(A_{y} f_{u}+A_{c} f_{c u}\right) \\
& N_{u}=4 \varphi\left(A_{y} f_{u}+A_{c} f_{c u}\right) \\
& N_{u}=(4 \varphi+1) \times\left(A_{y} f_{u}+A_{c} f_{c u}\right)
\end{aligned}
$$

Table 4. Comparison between the Test, FEM, and Formula

\begin{tabular}{|c|c|c|c|c|c|c|c|}
\hline Specimen No & $\begin{array}{c}e \\
(\mathrm{~mm})\end{array}$ & $\begin{array}{c}e_{x} \\
(\mathrm{~mm})\end{array}$ & $\begin{array}{c}e_{y} \\
(\mathrm{~mm})\end{array}$ & $\begin{array}{c}N_{u t} \\
(\mathrm{test}) \\
(\mathrm{kN})\end{array}$ & $\begin{array}{c}N_{u F} \\
(\mathrm{FEM}) \\
(\mathrm{kN})\end{array}$ & $\begin{array}{c}N_{u f} \\
(\text { formula }) \\
(\mathrm{kN})\end{array}$ & $\frac{\left|N_{u f}-N_{u t}\right|}{N_{u t}} \times 100 \%$ \\
\hline $\begin{array}{c}\text { Specimen-1 } \\
\text { Uniaxial bending }\end{array}$ & 186 & -83 & 167 & 980 & 740 & 949 & $3.16 \%$ \\
\hline $\begin{array}{c}\text { Specimen-2 } \\
\text { Biaxial bending }\end{array}$ & 185 & 131 & 131 & 940 & 699 & 891 & $5.21 \%$ \\
\hline $\begin{array}{c}\text { Specimen-3 } \\
\text { Axial compression }\end{array}$ & 0 & 0 & 0 & 2300 & 2113 & 2280 & $0.87 \%$ \\
\hline
\end{tabular}

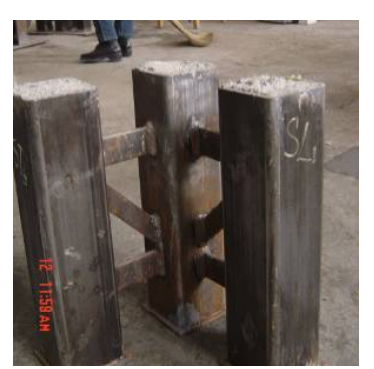

(a) L-shaped column

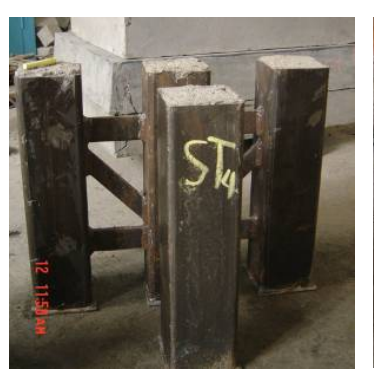

(b) T-shaped column

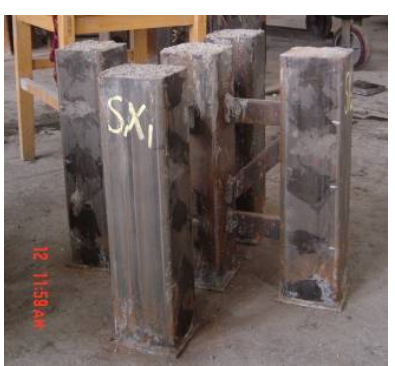

(c) X-shaped column

Figure 19. Axial Loading Test in Reference [12] 
Table 5. Comparison between the Reference Test and the Proposed Formula Results

\begin{tabular}{|c|c|c|c|c|c|c|c|c|c|}
\hline Specimen No & $\begin{array}{c}e \\
(\mathrm{~mm})\end{array}$ & $\begin{array}{c}\mathrm{h} \\
(\mathrm{mm})\end{array}$ & $\begin{array}{c}\mathrm{a} \\
(\mathrm{mm})\end{array}$ & $\begin{array}{c}\mathrm{b} \\
(\mathrm{mm})\end{array}$ & $\begin{array}{c}f_{u} \\
(\mathrm{MPa})\end{array}$ & $\begin{array}{c}f_{c u} \\
(\mathrm{MPa})\end{array}$ & $\begin{array}{c}N_{u t} \\
(\mathrm{Test}) \\
(\mathrm{kN})\end{array}$ & $\begin{array}{c}N_{u f} \\
(\text { Formula } \\
(\mathrm{kN})\end{array}$ & $\begin{array}{c}\text { Error } \\
(\%)\end{array}$ \\
\hline $\begin{array}{c}\text { L-shaped CFST } \\
\text { column }\end{array}$ & 0 & 400 & 100 & 100 & 429 & 49.7 & 3975 & 3960 & $3.77 \%$ \\
\hline $\begin{array}{c}\text { L-shaped CFST } \\
\text { column }\end{array}$ & 0 & 2000 & 100 & 100 & 429 & 49.7 & 3610 & 3370 & $6.64 \%$ \\
\hline $\begin{array}{c}\text { T-shaped CFST } \\
\text { column }\end{array}$ & 0 & 400 & 100 & 100 & 472 & 49.7 & 5580 & 5280 & $5.37 \%$ \\
\hline $\begin{array}{c}\text { T-shaped CFST } \\
\text { column }\end{array}$ & 0 & 2000 & 100 & 100 & 472 & 49.7 & 4600 & 4500 & $2.17 \%$ \\
\hline $\begin{array}{c}\text { X-shaped CFST } \\
\text { column }\end{array}$ & 0 & 400 & 100 & 100 & 429 & 49.7 & 6830 & 6660 & $2.49 \%$ \\
\hline $\begin{array}{c}\text { X-shaped CFST } \\
\text { column }\end{array}$ & 0 & 2000 & 100 & 100 & 429 & 49.7 & 6390 & 5800 & $9.23 \%$ \\
\hline
\end{tabular}

\section{CONCLUSIONS}

The behavior of SCFT columns subjected to axial load and eccentric load was experimentally investigated. The effects of the eccentric angle and distance were studied. The experimental results were compared with those of FEM analysis. The following conclusions could be drawn:

(1) Mono-columns could work together when the entire column bears the eccentric load. The SCFT column demonstrates good eccentric loading behavior. Thus, this kind of special-shaped column is suitable for residential buildings.

(2) The ultimate bearing capacity of Specimen S-1 and S-2 decreased by 57\% compared with that of Specimen S-3, which means that eccentric load was adverse.

(3) The failure mode of Specimen S-1 was uniaxial bending around axis $X^{\prime}-X^{\prime}$, that of Specimen S-2 was biaxial bending around axis A'-A', and that of Specimen S-3 was axial compression with minimal bending, as shown in Figure 10. Meanwhile, mono-columns could work together. The strain distribution and failure mode indicate that the failure of specimens under eccentric loading was caused by instability, whereas steel yielding caused the failure of axial loading specimens.

(4) The connection plate could be reduced to a lacing bar with an angle of $35^{\circ}$ to $45^{\circ}$, whereas the stiffener could be reduced to a lateral lacing bar, as shown in Figure 13.

(5) The results obtained by FEM analysis agreed with those obtained by the test. Thus, FEM analysis can effectively simulate the behavior of SCFT columns.

(6) According to the test and FEM analysis, eccentric load could be divided into three axial loadings subjected by mono-columns, and a simplified calculating formula was proposed to predict the ultimate bearing capacity of SCFT under compression. The calculated results were reasonably accurate. 


\section{ACKNOWLEDGMENTS}

This work was sponsored by the National Natural Science Foundation of China (grant nos. NSFC51308387).

\section{NOMENCLATURE}

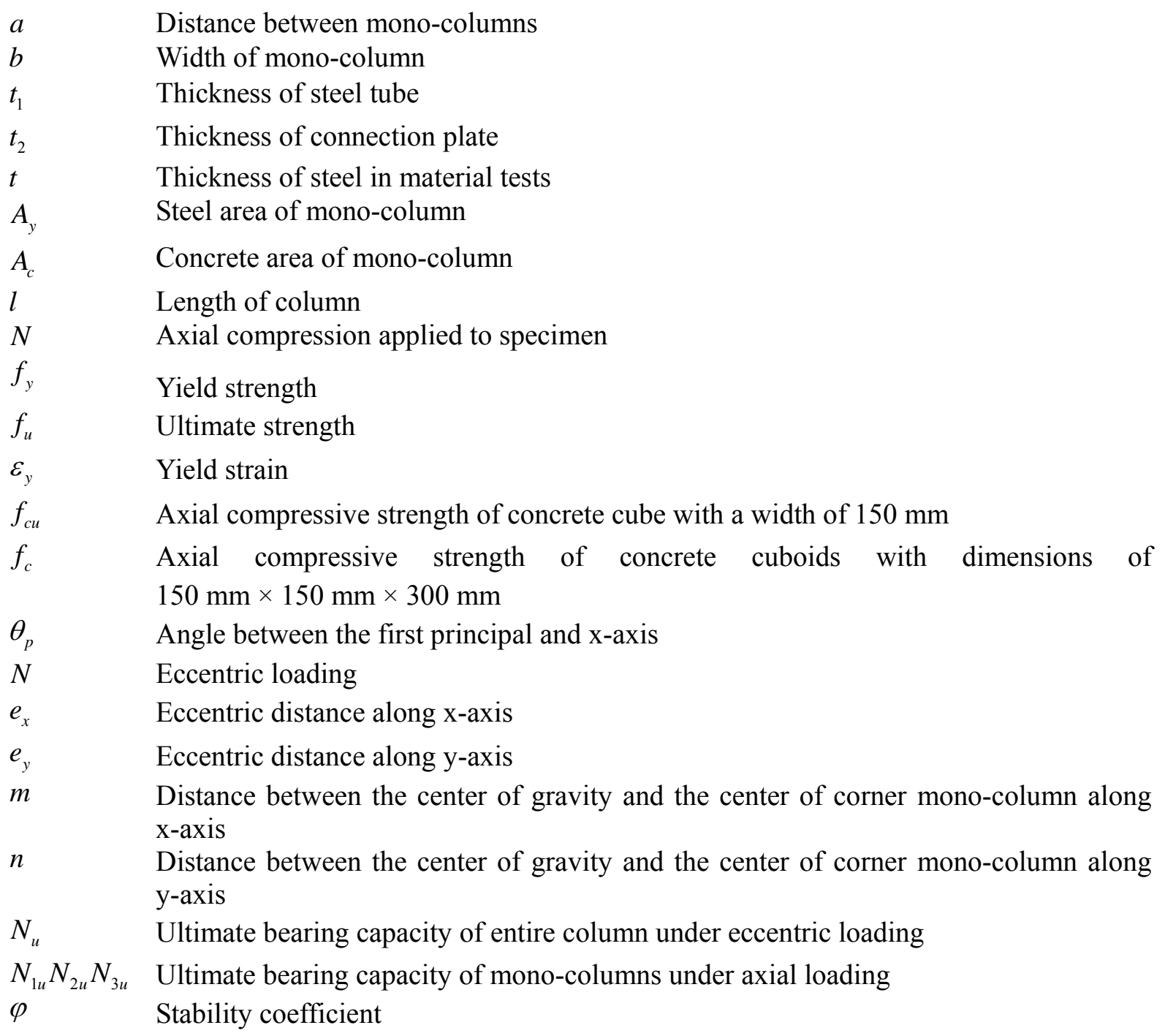

\section{References}

[1] Ramamurthy, L.N. and Hafeez, K.T.A., "L-shaped Column Design for Biaxial Eccentricity", Journal of Structural Engineering, 1983, Vol. 109, No. 8, pp. 1903-1917.

[2] Xue, J.Y., Chen, Z.P., Zhao, H.T., Gao, L. and Liu, Z.Q., "Shear Mechanism and Bearing Capacity Calculation on Steel Reinforced Concrete Special-shaped Columns", Steel and Composite Structures, 2012, Vol. 13, No. 5, pp. 473-487.

[3] Tokgoz, S. and Dundar, C., "Tests of Eccentrically Loaded L-shaped Section Steel Fibre High strength Reinforced Concrete and Composite Columns", Engineering Structures, 2012, 
Vol. 38, pp. 134-141.

[4] Shen, Z.Y., Lei, M., Li, Y.Q., Lin, Z.Y. and Luo, J.H.,” Experimental Study on Seismic Behavior of Concrete-Filled L-Shaped Steel Tube Columns", Advances in Structural Engineering, 2013, Vol. 16, No. 7, pp. 1235-1247.

[5] Zhou, T., Chen, Z.H. and Liu, H.B., "Seismic Behavior of Special Shaped Column Composed of Concrete-filled Steel Tubes", Journal of Constructional Steel Research, 2012, Vol. 75, pp.131-141.

[6] Chen, Z.H., Rong, B. and Apostolos, F., "Axial Compression Stability of a Crisscross Section Column Composed of Concrete-filled Square Steel Tubes", Journal of Mechanic of Materials and Structures, 2009, Vol. 4, No. 10, pp. 1787-1799.

[7] Chen, Z.H., Zhou, T. and Wang, X.D., "Application of Special Shaped Column Composed of Concrete-filled Steel Tubes", Advanced Materials Research, 2011, pp.196-199.

[8] Zhou, T., Li, X.F. and Xu, M.Y., "Heat Transfer Property of Special-shaped Column Composed of Concrete-filled Steel Tubes", Journal of Tianjin University, 2015, supplement, pp.74-80.

[9] Kim, C.S., Park, H.G., Chung, K.S. and Choi, I.R., "Eccentric Axial Load Capacity of High-strength Steel-concrete Composite Columns of Various Sectional Shapes", Journal of Structural Engineering, 2014, Vol. 140, No. 4.

[10] Halabi, Z., Ghrib, F., El-Ragaby, A. and Sennah, K., "Behavior of RC Slab-column Connections Strengthened with External CFRP Sheets and Subjected to Eccentric Loading", Journal of Composites for Construction, 2013, Vol. 17, No. 4, pp.488-496.

[11] Ernest, B., Lluis, G., Pere, R. and Christian, E., "Experimental and Analytical Study of TRM Strengthened Brickwork Walls under Eccentric Compressive Loading”, Construction and Building Materials, 2013, Vol. 44, pp. 35-47.

[12] Song, X.B., Gu, X.L., Li, Y.P., Chen, T., and Zhang, W.P.,” Mechanical Behavior of FRP-strengthened Concrete Columns Subjected to Concentric and Eccentric Compression Loading”, Journal of Composites for Construction, 2013, Vol. 17, No. 3, pp. 336-346.

[13] Liu, H.B., Chen, Z.H., Wang, X.D. and Zhou, T., "Theoretical Analysis and Experimental Research on Stability Behavior of Structural Steel Tube and Coupler Falsework with X-bracing”, Advanced Steel Construction, 2010, Vol. 6, No. 4, pp. 946-962.

[14] Rong, B., "Theoretical Analysis and Experimental Study on Special-shaped Column Composed of Concrete-filled Square Steel Tubes", Doctoral Dissertation, 2008, Tianjin University. (In Chinese) 